\title{
UM OLHAR SOBRE CURRÍCULO: FERRAMENTA PARA EMPODERAMENTO DO PROFESSOR
}

\author{
PASSONI, Taisa Pinetti - UEL \\ AUDI, Luciana Cristina da Costa - UEL \\ D'ALMAS, Juliane - UEL \\ GAMERO, Raquel - UEL
}

\begin{abstract}
RESUMO: A formação de professores de língua inglesa vem cada vez mais se caracterizando pela demanda por profissionais polivalentes: que possuam a habilidade de aliar o aprofundamento em estudos das disciplinas focadas no idioma ao domínio de conhecimentos que venham suprir às necessidades de uma sociedade composta por sujeitos singulares pertencentes a classes sociais que massificam essas singularidades. Portanto, formar professores de língua inglesa torna-se uma tarefa de extrema complexidade, pois deve fazer parte de um projeto político mais amplo para a sociedade, conforme salientam Giroux e McLaren (2002 apud FURTOSO E GIMENEZ, 2008). Assim sendo, compreendemos que o estudo de currículo pode ser definido como um componente essencial para este intuito, mais especificamente neste trabalho, podendo tornar-se uma ferramenta que auxilia na compreensão do que vem a ser o currículo, para então apropriar-se dele como instrumento a seu favor. A palavra currículo possui uma infinidade de definições, bem como uma diversidade de teorias que buscam compreender seu significado, temas os quais serão aqui abordados. O presente trabalho é uma revisão bibliográfica, portanto, de base secundária, e tem por objetivo apresentar um panorama acerca das concepções de currículo, a fim de relacioná-las com as pesquisas desenvolvidas dentro desta temática e com a sua relevância para a formação de professores. Consideramos que por intermédio da compreensão da importância que o currículo tem como ferramenta do trabalho do professor, bem como da participação deste profissional na construção do mesmo, será possível conceber uma formação de professores condizente com as demandas sociais vigentes.
\end{abstract}

PALAVRAS-CHAVES: Formação de Professores de língua inglesa; Língua Inglesa; Pesquisa em currículo; Currículo.

ABSTRACT: The English language teacher's education is increasingly being characterized by the demand for professional multi-purpose: having the ability to combine a deepening of the subjects in studies focusing on the language to the mastery of knowledge that will meet the needs of a society composed by unique subject belonging to social classes that massify these singularities. Therefore, training teachers of English becomes an extremely complex task, it must be part of a broader political project for society, as pointed out by Giroux and 
McLaren (2002 apud FURTOSO E GIMENEZ, 2008). From this perspective, we understand that the study of the curriculum can be defined as an essential component for this purpose, more specifically in this study; it reveals itself as a tool that can assist the comprehension of the curriculum, in order to appropriate of it as an instrument for one's professional life. The word curriculum has a multitude of definitions, as well as a variety of theories that seek to understand its meaning, themes which will be addressed here. This study is a literature review, thus a secondary base data, and aims to present an overview of the curriculum concepts, in order to relate them to the research developed within this theme and its relevance in teacher training. We believe that through the understanding of the curriculum importance in teacher's work as a tool, as well as the participation of this professional in designing the curriculum it will be possible to conceive teacher education that may be consistent with the current social demands.

KEY-WORDS: English language teacher's education; English Language; Curriculum; Curriculum Research.

\section{Introdução}

"O currículo é lugar, espaço, território. O currículo é relação de poder. O currículo é trajetória, viagem, percurso. O currículo é autobiografia, nossa vida, curriculum vitae: no currículo se forja nossa identidade. O currículo é texto, discurso, documento. O currículo é documento de identidade."

Tomaz Tadeu da Silva

Com o intuito de evidenciar a importância das concepções de currículo na formação de professores, buscamos verificar o andamento das pesquisas acerca desta temática a fim de tratar das possíveis contribuições dos estudos desta natureza no que se refere à constituição da licenciatura em língua inglesa (LI), este artigo tem por objetivo elaborar um levantamento tanto da literatura acerca de currículo, quanto das publicações decorrentes deste tema.

Este trabalho é uma pesquisa bibliográfica, que de acordo com Reis (2008) se caracteriza por desenvolver uma síntese e revisão de uma área de conhecimento. Trabalhos desta natureza não são exaustivos, são situados, parciais e focados em determinadas perspectivas, além disso, possuem uma metodologia importante, pois “... permitem conhecer determinada questão em termos histórico e metodológico, servem para construir uma rede intertextual que pode auxiliar o leitor a ver um campo de nova maneira” (LATHER, 1999 apud REIS, 2008, p. 52). 
No que remete aos cursos de formação, a importância de pesquisas com o foco em perspectivas curriculares determina-se vistas às possibilidades de empoderamento do professor uma vez que demonstram o potencial do currículo como instrumento político, em relação ao qual os profissionais da educação não podem permanecer indiferentes, como meros executores de prescrições.

Sendo assim, almejando compreender diferentes formas de se conceber currículo bem como a análise deste processo, neste trabalho apresentamos um breve histórico acerca das teorias de currículo, as diferentes concepções para este complexo termo, traçar um levantamento bibliográfico de teses e dissertações sobre este assunto, para assim apontar sugestões de encaminhamentos para os estudos desta natureza.

\section{Panorama das Teorias do Currículo}

Partindo da abordagem histórica apresentada por Silva (2004), iremos traçar um panorama sobre como o currículo tem sido definido em diferentes momentos, em diferentes teorias. Em seguida apresentaremos algumas concepções de currículo de acordo com estudiosos da área (Dewey, 1959; Freire, 1986; Giroux, 1997; Goodlad, 1979; Piconi, 2009) as quais perpassam estes momentos.

Historicamente, de acordo com Silva (2004), o currículo tornou-se objeto de estudo e pesquisa nos Estados Unidos a partir dos anos vinte, com a obra de Bobbitt em 1918, The curriculum, a qual expressa as ideias de um grupo de pessoas ligadas à administração da educação, num período de industrialização e grandes movimentos imigratórios naquele país. Baseado nos ideais de Taylor $^{1}$, o modelo de currículo apresentado constitui-se da “especificação precisa de objetivos, procedimentos e métodos para a obtenção de resultados que possam ser precisamente mensurados" (SILVA, 2004, p. 12). O currículo, então, é tratado como um processo industrial e administrativo, segundo Silva (op.cit.) Bobbit propunha que o sistema educacional, tal como uma fábrica, pudesse especificar precisamente os resultados que se pretendia obter, e os objetivos do ensino deveriam se basear num exame das habilidades necessárias para exercer com eficiência as ocupações profissionais da vida adulta.

Segundo Silva (2004) anteriormente a essa obra, em 1902, John Dewey, já tinha escrito The child and the curriculum, que não causou tanto impacto, pois, contrariamente a

\footnotetext{
${ }^{1}$ De acordo com Mateus (2005) Frederich Taylor defendia uma organização científica do trabalho com bases na padronização de tarefas as quais deveriam ser cronometradas.
} 
Bobbitt, considerava os interesses e as experiências das crianças e jovens. A influência de Dewey, portanto não foi tão marcante na formação do currículo como campo de estudos quanto à de Bobbitt porque não concebia a educação como preparação para a vida adulta. $\mathrm{O}$ modelo de currículo de Bobbitt dava um caráter mais científico à educação e encontrou sua consolidação com Ralph Tyler, citado em Silva (op.cit.), que publicou uma obra em 1949, a qual dominou o campo do currículo nos Estados Unidos e exerceu forte influência em vários países, inclusive no Brasil. A partir da obra de Tyler os estudos sobre currículo focaram-se nas idéias de organização e desenvolvimento, buscando responder quatro questões básicas, que correspondem à divisão tradicional da atividade educacional: currículo, ensino/instrução e avaliação; versando sobre os objetivos e experiências educacionais, organização dessas experiências e como podemos averiguar se esses objetivos são alcançados.

Com a explosão de revoluções - feministas, culturais e sociais - da segunda metade do século passado, surgiram também, na década de 60, diversos livros, ensaios e teorizações que colocavam em xeque a tradicional estrutura educacional. Concomitantemente a esse fato, explodiram as teorias críticas do currículo, em contraposição aos fundamentos das teorias tradicionais (modelos de Bobbitt e Tyler), que se concentravam nas formas de organização e elaboração do currículo. Segundo Silva (2004, p. 30), "para as teorias críticas o importante não é desenvolver técnicas de como fazer o currículo, mas desenvolver conceitos que nos permitam compreender o que o currículo faz". O autor indica que surgem os estudos marxistas de Althusser, sobre a atuação ideológica da escola através do currículo, que atinge toda a comunidade por um longo tempo; enfatizando o papel do conteúdo das matérias escolares na transmissão da ideologia capitalista, de forma que a escola transmita as crenças que nos levam a ver as imposições sociais de forma neutralizada.

Em sua revisão, Silva (op.cit.) indica que são os economistas americanos Samuel Bowles e Herbert Gintis, que apresentaram uma visão diferente dos entendimentos marxistas entre produção e educação. Em sua obra, A Escola Capitalista na América, os autores enfatizam que a escola é espaço para a reprodução das relações sociais da sociedade capitalista, pois no âmbito escolar se cultivam hábitos do mundo do trabalho, onde há os subordinados e os empreendedores.

Com ênfase na cultura, Silva (2004) indica que os sociólogos franceses Pierre Bourdieu e Jean-Claude Passeron, entendem que sendo o currículo baseado na cultura das classes dominantes, a escola acaba funcionando como um mecanismo de exclusão; pois a cultura que tem valor social é justamente a cultura destas classes, que se manifesta em estado objetivado - obras de arte, obras literárias, peças teatrais, títulos, certificados e diplomas. 
Enquanto os estudantes da elite veem seu capital cultural valorizado, os estudantes das camadas sociais inferiorizadas vivenciam processo contrário. Assim, a escola é o lugar onde não apenas a cultura da elite deve ser reproduzida, mas também enfatiza a repetição dos papéis sociais dos indivíduos numa sociedade de classes.

De acordo com Silva (2004) a crítica às teorias tradicionais de currículo e ao papel ideológico é fortemente marcada pelos ideais de Michael Apple, a partir de sua obra Ideologia e currículo de 1979. O autor indica que, enquanto os modelos técnicos limitam-se à questão de como organizar o currículo, na perspectiva de Apple, o foco está em porque tais conhecimentos são considerados importantes e não outros, quais interesses guiaram a seleção de determinado conhecimento em detrimento a outro. Essa crítica inicial do currículo deu-se dividida entre duas ênfases, as críticas que enfatizavam o currículo oculto; e as críticas que deram mais importância ao currículo explícito, ou seja, ao conteúdo do currículo. Para Apple, o currículo não pode ser compreendido e transformado se não questionarmos suas conexões com as relações de poder.

Outro autor de destaque entre os americanos que desenvolveu uma teorização crítica sobre o currículo é Giroux (1997), cujo foco esteve centrado numa reação às perspectivas empíricas e técnicas sobre currículo, até então dominantes. Em sua análise, essas perspectivas ao se concentrarem em critérios de eficiência e racionalidade burocrática, não levavam em consideração o caráter histórico, ético e político das ações humanas e sociais; contribuindo para a reprodução das desigualdades. Giroux (1997) critica o modelo de currículo de Bowles e Gintis por não deixarem espaço para a mediação e a ação humana em seu princípio de correspondência, onde o que ocorria na escola e no currículo era pré-determinado pelo que acontecia na economia e na produção. Influenciado pelos conceitos da escola de Frankfurt, Giroux compreende o currículo através dos conceitos de emancipação e libertação. Para que as pessoas possam se libertar do poder e do controle das elites através de um processo pedagógico emancipador, é essencial que estas se tornem conscientes das influências exercidas pelas instituições e pelas estruturas sociais.

No contexto brasileiro, o sociólogo Paulo Freire (1970) ganha destaque com sua crítica ao currículo em vigência, a qual é sintetizada em seu conceito de "educação bancária". Esta visão epistemológica concebe o conhecimento constituído de informações e fatos a serem transferidos do professor para o aluno; onde o professor é tido como depositante e o aluno é o depositário, aquele que recebe o conhecimento como um depósito, e então o guarda.

Face à diversidade cultural do mundo contemporâneo, Silva (2004) relata que um movimento de forte crítica ao currículo universitário tradicional se originou nos Estados 
Unidos, contendo a crítica dos grupos culturais educacionais subordinados - mulheres, negros e homossexuais. Fez-se então necessário pensar um currículo multiculturalista, dividido nas concepções pós-estruturalista, ou seja, com ênfase nos processos discursivos de produção da diferença, e materialista, inspirada no marxismo, com ênfase nas trocas, nos processos institucionais, econômicos e estruturais da base da educação. Em termos curriculares, o multiculturalismo pretendia substituir o estudo da produção intelectual ocidental pelas obras consideradas intelectualmente inferiores produzidas pelas minorias. Essa perspectiva cultural, ao contrário das reivindicações educacionais anteriores, mostrou que a obtenção da igualdade dependia de modificações substanciais no currículo existente, e não de igualdade de acesso a este currículo. De certa forma, as perspectivas críticas sobre o currículo tornaram-se questionadas por ignorarem outras dimensões da desigualdade que não aquelas ligadas à classe social. Não se levava em consideração o papel do gênero e da raça no processo de (re)produção das desigualdades.

A literatura pós-crítica centrou-se em analisar materiais como os livros didáticos, por exemplo, que faziam circular certos estereótipos como aqueles em que as mulheres figuravam papéis profissionais inferiores aos dos homens; levando professores e alunos a internalizarem preconceitos de gênero e estereótipos, em que os professores passam a esperar resultados diferentes de meninos e meninas, e que de certa forma determinavam a carreira educacional dos mesmos, reproduzindo as desigualdades de gênero, impondo, assim, a construção de uma sociedade de acordo com as características do gênero dominante - masculino.

Deste modo, de acordo com Silva (op. cit.) qualquer perspectiva, seja crítica ou póscrítica, seria considerada parcial e limitada se ignorasse as conexões entre conhecimento, identidade de gênero e poder teorizado por essas análises. O autor (op.cit., p. 97) sustenta que "o currículo é, entre outras coisas, um artefato de gênero: um artefato que, ao mesmo tempo, corporifica e produz relações de gênero".

Nas análises mais recentes, os conceitos de raça e etnia também têm sido muito problematizados, e é através do vínculo entre conhecimento, identidade e poder que esses temas ganham lugar na teoria curricular. Um currículo centrado em torno de questões sobre mecanismos de construção de identidades nacionais, raciais e étnicas faria com que um currículo multiculturalista deixasse de ser folclórico para se tornar profundamente crítico e político, centrando-se na discussão de causas institucionais, históricas e discursivas também do racismo. Para uma perspectiva crítica, não existe identidade fora da história e da representação, sendo que a representação é sempre social (MOSCOVICI, 2003), construída linguística e discursivamente, dependente das relações de poder instituidas. 
Como podemos perceber, o currículo tem sido tradicionalmente concebido como um espaço onde se ensina a pensar, se transmite o pensamento, se aprende o raciocínio e a racionalidade. Entendemos, portanto, que o currículo não pode se limitar a questionar o conhecimento como apenas um objeto socialmente construído, mas deve aventurar-se a explorar aquilo que ainda não foi construído.

No pós-modernismo surge um movimento intelectual que na sua versão social e política vem questionar tais princípios e pressupostos desenvolvidos até então (SILVA, 2004). Por tratar-se de uma crítica ao sujeito centrado e autônomo, a identidade que emerge desse movimento torna-se descentrada, múltipla e fragmentada. Enquanto o currículo até então existente está focado na divisão de classes sociais, na perspectiva pós-moderna o problema não se limita apenas no currículo existente, mas envolve a própria teoria crítica deste.

Este movimento pós-moderno vem questionar a pedagogia crítica e sua ênfase no pressuposto de que o sujeito até então submisso à dominação das classes sociais detentoras de poder, torna-se emancipado e libertado pela pedagogia crítica. É o pós-modernismo que vem, dessa forma, assinalar o fim da pedagogia crítica e o início da pedagogia pós-crítica.

Este movimento pode ser considerado uma continuidade e ao mesmo tempo uma transformação do movimento teórico que dominou os anos 50 e 60, baseados no estruturalismo pautado pelas ideias de Ferdinand Saussure, que enfatizavam as regras de formação estrutural da linguagem. Como o próprio nome sugere, o estruturalismo privilegiava a noção de estrutura, "não dos elementos individuais de um fenômeno ou objeto, mas das relações entre aqueles elementos" (SILVA, 2004, p.118). O pós-estruturalismo vem transcender o estruturalismo, pois amplia a centralidade que a linguagem apresenta neste movimento.

O autor indica que, também inserida nas teorias pós-críticas, a teoria pós-colonialista objetiva analisar as relações de poder entre as diferentes nações que se configuraram pela conquista colonial européia. Essa vertente enfatiza as teorias e análises literárias. Juntando-se às análises pós-moderna e pós-estruturalista, vem questionar as relações de poder e as formas de conhecimento que privilegiavam o sujeito imperial europeu, focalizando as complexas relações entre a exploração econômica e a ocupação militar de um lado, e a dominação cultural de outro. É justamente esta teoria que vislumbra um currículo descolonizado.

A relação entre os estudos culturais, que tiveram origem na Inglaterra, e o currículo é enfatizada por apresentar o conhecimento como resultado de um processo de criação e interpretação social, no qual todas as suas formas são processadas como resultado dos aparatos que as constituíram como tal. Silva (2004) destaca que uma das vantagens concepção 
de currículo inspirada nesses estudos culturais é que nessa perspectiva não ocorre cisão entre o conhecimento escolar e o conhecimento cotidiano das pessoas envolvidas no currículo. Por não apresentar essa distinção, todas as instâncias culturais tornam-se também pedagógicas porque apresentam uma pedagogia e de uma forma ou de outra também ensinam alguma coisa. Por esse prisma, todo conhecimento é cultural e está intimamente ligado a questões de poder. Porém, tal qual acontece com o pós-modernismo, o pós-estruturalismo, e o póscolonialismo, também os Estudos Culturais imprimem pouca influência tanto na elaboração de políticas de currículo quanto no currículo do cotidiano de sala de aula.

O crescimento da informatização e era digital trouxe-nos grandes dificuldades para separarmos o conhecimento escolar do cotidiano e da cultura. Segundo Silva (2004), diversos autores prestaram-se a fazer análises dessa pedagogia ou desse currículo cultural, por intermédio de uma "crítica cultural do currículo", entre os quais figuram nomes conhecidos como Henry Giroux, Joe Kincheloe, Roger Simon. Essa teoria curricular crítica revela tanto a indústria cultural quanto o currículo escolar como artefatos carregados de significação e produtores de identidades e subjetividades no contexto de relações de poder. Desta forma, a crítica curricular não deixa de ser também uma crítica cultural.

Todas as teorias até aqui descritas nos apontam para questionamentos acerca das relações de poder e currículo. As teorias críticas indicam que algumas formas de poder são de fato mais ameaçadoras do que outras. Deste modo, tanto as teorias críticas quanto as póscríticas nos mostraram que o currículo engloba questões de saber, identidade e poder, as quais devem ser questionadas. Sendo espaço de conflitos, o currículo desempenha importante papel na reprodução da estrutura de classes da sociedade capitalista, transmitindo a ideologia dominante, tornando-se também um lócus político; pois reproduz culturalmente as estruturas sociais.

Em suma, ao longo de todo esse histórico das teorias críticas e pós-críticas, concluímos que já não é mais possível olhar para o currículo de forma neutra; torna-se necessário atentarmos-nos para o fato de que o currículo carrega em si significados outros, não só aqueles os quais as teorias tradicionais de currículo nos informavam. Portanto podemos afirmar que currículo é expressão de nossa própria identidade, sendo esta aqui entendida como multifacetada, influenciada por fatores históricos, psicológicos e culturais (COOPER \& OLSON, 1996).

\section{Diferentes Concepções de Currículo}


Uma formação de professores que coloque em pauta as diferentes perspectivas curriculares requer ampla discussão acerca das diversas concepções de currículo. Por si só, a palavra currículo abarca inúmeras definições, além de uma gama de teorias as quais embasam seus significados. Assim sendo, pretendemos aqui apresentar um panorama geral a respeito de algumas das possibilidades de conceituações de currículo, que em nossa concepção parecem essenciais e certamente demandam maior aprofundamento. Ou seja, as perspectivas curriculares abordadas neste estudo não se esgotam, apenas esboçam o início de uma discussão que deve ser continuada nos cursos de formação.

Inicialmente podemos considerar a idéia de Dewey (1959) de que currículo é um conjunto de aprendizagens pretendidas, entretanto, tal concepção não é suficiente para sintetizar a complexidade de tal conceito. Portanto, iremos apresentar diferentes referenciais defendidos por alguns estudiosos de currículo.

De acordo com Goodlad (1979), existem cinco possíveis concepções para o termo currículo: o ideal, o formal, o percebido, o operacional e o experienciado. Para o autor, o currículo ideal, também chamado de ideológico, é aquele que previamente estabelece um planejamento idealizado sobre como o processo de ensino/aprendizagem deve ocorrer. Tal definição se aproxima do conceito de currículo formal, aquele que apresentado como um documento escrito aprovado por legisladores, assim possui status de "lei” e projeta as crenças, os valores e as atitudes vislumbradas aos aprendizes. Outra perspectiva é a do currículo percebido - o qual pode se relacionar com os dois outros já apresentados, porém não necessariamente -, isto porque trata daquilo que está na mente daqueles que estão envolvidos com o ensino, sejam eles alunos, professores, pais ou diretores. Definição esta que se relaciona à concepção de currículo operacional, pois este trata do que os professores de fato realizam em sala de aula. Já a última concepção é a de currículo experienciado, aquele que aborda a experiência vivenciada pelos alunos na sala de aula.

Ao passo que Silva (2004), apresenta a perspectiva do currículo oculto. Para o autor, tal currículo contempla os aspectos implícitos e não oficiais, que contribuem para a aprendizagem dos comportamentos e dos valores sociais presentes no ambiente escolar.

Outra referência de extrema relevância para o estudo de currículo é Freire (1986). No vasto legado freiriano pode-se encontrar princípios em relação ao que deve ser currículo. Ao estabelecer sua concepção de currículo, o autor critica o currículo tradicional centrado em disciplinas. Nas palavras do autor (ibidem, 1986, p.97): 
O currículo padrão, o currículo de transferência é uma forma mecânica e autoritária de pensar sobre como organizar um programa, que implica, acima de tudo, numa tremenda falta de confiança na criatividade dos estudantes e na capacidade dos professores! Porque, em última análise, quando certos centros de poder estabelecem o que deve ser feito em classe, sua maneira autoritária nega o exercício da criatividade entre professores e estudantes. $\mathrm{O}$ centro, acima de tudo, está comandando e manipulando, à distância, as atividades dos educadores e dos educandos.

Tomando como base esta afirmação, podemos constatar que as ideias de Freire (op.cit.) em relação à composição de um currículo norteiam-se essencialmente por uma oposição ao currículo denominado tradicional. Tal perspectiva tem sido compartilhada por outros estudiosos, não apenas no Brasil, mas também no exterior, os quais apontam para uma forte influência da chamada teoria crítica do currículo. Para estudos desta linha epistemológica, a concepção/construção de currículo deve extrapolar a grade curricular, a seleção de conteúdos e organização de disciplinas, portanto, o currículo é concebido como um forte instrumento político do professor, o qual deve ser criticamente pensado.

O paradigma sócio-histórico-cultural ${ }^{2}$ (Engeström, 1987; Newman e Holzman, 1993/2002; Rogoff, 1995; Vygostky, 1998; Wertsch, 1991) também traz as suas contribuições para a educação como um todo, sendo assim, também pode revelar diferentes possibilidades de concepção currículo. De acordo com Piconi (2009), esta visão opõe-se a ideia de currículo como instrumento de transmissão de valores ou como um apanhado de técnicas eficientes para o ensino, e afirma o currículo como processo de desenvolvimento de espaços para a produção de conhecimento.

Nesta perspectiva, o currículo é definido como algo inacabado, sempre em constante construção em consonância com o que é localmente significativo para uma determinada comunidade de professores e aprendizes. Dessa maneira, o currículo é interpretado como uma busca colaborativa de possibilidades para construção de sentidos para aqueles envolvidos no processo de ensino/aprendizagem. Sendo assim, ao abordar um currículo para a formação de professores de língua inglesa, Piconi (2009, p.49) define currículo como "instrumento-eresultado do processo de produção de conhecimento na atividade de formação", concepção a qual pode ser adotada em face de diferentes contextos de educação formal. Ou seja, entender currículo como "instrumento-e-resultado" tem a ver com perspectivas que vislumbram o ensino/aprendizagem de uma maneira dialética e não estática.

\footnotetext{
2 Optamos por usar este termo amplo, o qual pode abranger estudos das tradições histórico-cultural, sociohistórica e sociocultural.
} 
No que se refere especificamente à formação de professores, a análise e/ou a elaboração de currículo aos nossos olhos está estritamente relacionada à proposta teórico crítica de Giroux (1997), a qual vislumbra um potencial emancipador às novas possibilidades curriculares através de uma oposição à "racionalidade tecnocrática".

Os pressupostos de Giroux (1997) relacionam-se às ideias freirianas de que não é possível conceber a escola de forma isolada da sociedade, compreendendo-a de maneira situada, o que corrobora com a visão epistemológica sócio- histórico-cultural.

Sendo assim, formar professores colocando em foco as diferentes perspectivas curriculares visa combater as tradições que educam professores de maneira a ignorar como se constroem e se organizam os princípios que sustentam a escola, como o currículo e sua avaliação, compactuando com uma visão limitada que corrobora com a (re)produção de preconceitos e esteriotipos sociais. Ao enfocar as pesquisas sobre currículo em cursos de formação de professores, será possível lidar de modo mais coerente com a problemática apresentada por Giroux (1997):

Quando professores não equacionam suas concepções básicas a respeito do currículo e da pedagogia, eles fazem mais do que transmitir atitudes, normas e crenças. Eles inconscientemente podem acabar endossando formas de desenvolvimento cognitivo que mais reforçam do que questionam as formas existentes de opressão institucional. (ibidem, p. 48).

Portanto, formar professores neste sentido não significa apagar as diferenças em busca de uma falsa neutralidade, mas sim reforçar a necessidade de reconhecer explicitamente que as escolhas que fazemos são marcadas por valores e que temos responsabilidades enquanto professores neste processo essencialmente ideológico que é educar.

Todas estas perspectivas de currículo não são excludentes, não se trata de adotar uma delas como correta, todas elas têm uma relação com o foco adotado, isto porque, de acordo com Goodlad (1979) o entendimento de currículo está "nos olhos de quem o vê", ou seja, cabe àqueles que estudam currículo a seleção do foco para seus trabalhos, sejam eles de elaboração ou de análise de currículo.

\section{Levantamento Bibliográfico sobre currículo na formação de professores de LI}

No intuito de trazer um panorama do que vem a ser as pesquisas sobre currículo no Brasil, desenvolvemos um levantamento bibliográfico, a partir da ferramenta de busca do 
Banco de Teses da CAPES $^{3}$, que ocorreu em abril de 2010, pelo termo currículo na formação de professores. Essa busca foi iniciada pelo critério assunto, sem delimitação de período, com todas as palavras e resultou em 2524 referências, provenientes de diversas áreas do conhecimento. O mesmo termo entre aspas não ofereceu resultados.

O termo utilizado foi bastante abrangente e nossa área de pesquisa se restringe a formação de professores de inglês, portanto, optamos por especificar a busca. Desse modo, utilizamos o termo "currículo na formação do professor de Inglês", pelo critério assunto, sem delimitação de período, com todas as palavras, o que resultou em 73 referências (60 dissertações de mestrado e 13 teses de doutorado), o mesmo termo entre aspas não ofereceu resultados.

A partir desse resultado, delimitamos o período de conclusão dos trabalhos, seguindo uma prática da academia, observamos os últimos cinco anos de produção acadêmica, ressaltando que a ferramenta de busca utilizada é encontrada no portal oficial do ministério da educação, que se propõe a possibilitar o acesso às pesquisas desenvolvidas no país. Os resultados estão apresentados no gráfico:

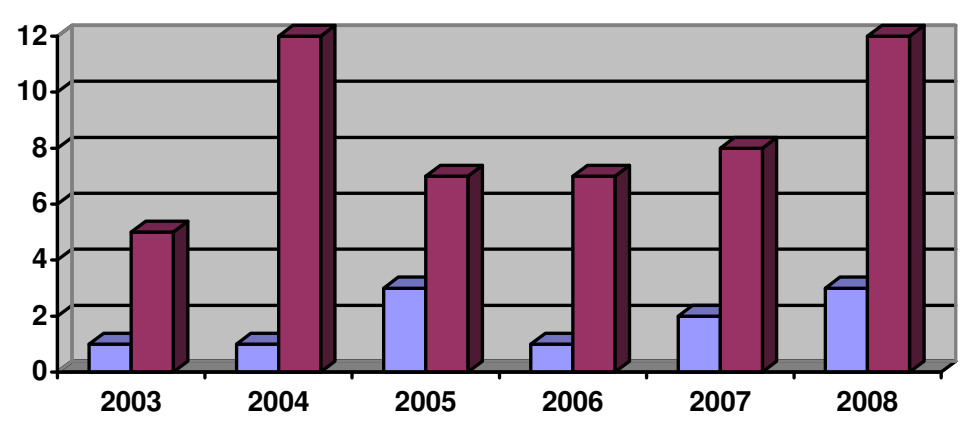

Os anos de 2009 e 2010 não registram pesquisas nessa área até o momento, devido a um atraso na disponibilização dos trabalhos. Os anos em que se concentram as dissertações em currículo na formação do professor de Inglês são 2004 e 2008, com 12 dissertações de mestrado cada, e 2004 e 2008, com três teses de doutorado cada. Não havendo uma representação de aumento das pesquisas, não podemos também afirmar que houve uma diminuição. O observável é uma inconsistência no padrão de repetição do tema, que não é uma preocupação recente, como é possível constatar na literatura consultada.

Descrevemos a seguir cinco estudos que em nossa concepção ilustram o panorama apresentado anteriormente a respeito da pesquisa em currículo no Brasil, seja pelo caráter

\footnotetext{
${ }^{3}$ Coordenação de Aperfeiçoamento de Pessoal de Nível Superior http://servicos.capes.gov.br/capesdw/
} 
metodológico da pesquisa, seja pelo foco da pesquisa, seja pelas questões epistemológicas, aspectos curriculares relevantes para a formação de professores, pois tratam respectivamente das seguintes temáticas: a dimensão política que constitui o currículo, a organização e desenvolvimento do estágio, o currículo como espaço de formação de educadores críticos e envolvidos com questões de cidadania, análise documental da formação de professores inglesa, e por fim, representações sociais de professores sobre o ensino da língua inglesa como componente curricular do ensino fundamental.

O primeiro deles é o de Costa (2004) que compara currículos universitários. A pesquisa é motivada pelas mudanças na Lei de Diretrizes e Bases da Educação Nacional $\mathrm{n}^{\circ}$ 9.394/96 e nas Diretrizes Curriculares para os Cursos de Formação de Professores, examinando as interferências legais na nova proposta curricular para a formação dos futuros professores de língua inglesa. O estudo apresenta currículo como uma seleção de conhecimentos necessários para a formação de um profissional. $\mathrm{O}$ resultado revelou que os aspectos legais contribuíram para que as instituições formadoras montassem novas propostas curriculares visando atender os dispositivos legais, apresentando algumas modificações. Contudo, os resultados apontam para algumas questões ainda precisam ser consideradas: ausência de estudos referentes à Lingüística Aplicada, carga horária reduzida destinada aos estudos de língua inglesa, a antecipação das atividades de práticas para os primeiros semestres dos cursos, a pouca importância dada à educação virtual, entre outras.

Em seguida, trazemos a dissertação de Fernandes (2008), a qual procura contribuir com os estudos sobre as diferentes formas de organização e desenvolvimento de Estágios Curriculares (EC) em Cursos de Licenciatura em Letras. Essa pesquisa concluiu que embora existam normativas legais específicas para o desenvolvimento dos EC, essas não são de fácil cumprimento. As instituições estudadas por Fernandes têm cumprido algumas delas (400 horas e início do EC a partir da $2^{\mathrm{a}}$ metade dos cursos), mas falta estabelecer um contato maior, mais integrado com as escolas. Segundo a autora, não basta o mero cumprimento das horas de EC nas mesmas, mas sim, estar articulado com as demais atividades propostas nelas e trabalhar de forma conjunta, buscando estabelecer vínculos e mecanismos que colaborem com o processo de formação dos futuros docentes.

Em um estudo de outra autora (FERNANDES, 2004), é possível perceber que um de seus focos é investigar em que medida o currículo do curso de licenciatura em Letras, especificamente da universidade inserida na pesquisa, contribui para a construção de educadores críticos e envolvidos com questões de cidadania. Outro foco recai sobre as situações de ação de linguagem que 12 professores experientes de diferentes contextos 
educacionais acham que professores de inglês podem vivenciar na vida profissional e social, e como essas práticas podem contribuir para a educação numa visão cidadã e fomentar uma revisão curricular no curso de Licenciatura em Letras. Os resultados da pesquisa documental mostram que o projeto pedagógico do currículo analisado busca a formação de professores com conhecimento, habilidades e competências para educar para a cidadania. Entretanto, os conteúdos programáticos das ementas e da bibliografia básica não estão de acordo com essas expectativas. A pesquisa de campo traz contribuições para professores, coordenadores, instituições educacionais na avaliação e futuro desenvolvimento de políticas e prática relacionadas ao currículo de língua inglesa na licenciatura.

Holanda (2001) relata em sua tese o sistema de formação de educadores na Inglaterra e no Brasil por meio da análise de documentos e reformas que geriram modificações nos sistema educacional no país europeu, buscando encontrar um paralelo por meio do qual se possa utilizar elementos bem sucedidos nos programas ingleses de formação de educadores, adequando-os à realidade brasileira.

Por fim, a última pesquisa que selecionamos para o contexto deste artigo foi a de Emílio (2008), dissertação que tem como objetivo realizar uma aproximação às representações sociais dos professores sobre o ensino da língua inglesa como componente curricular do ensino fundamental. Desse modo, a pesquisadora percebeu que há a necessidade de ações voltadas para as políticas públicas, para o contexto organizacional escolar e para a formação profissional, de forma articulada e que envolvessem os atores do processo educacional a fim de que se desmistificasse a idéia de que não se aprende inglês no ensino regular.

Trouxemos, portanto, 2 estudos comparativos (COSTA, 2004; HOLANDA, 2001), o que nos mostra que a comparação pode revelar novos caminhos para a organização curricular a fim de promover melhorias, 2 trabalhos que focam na maneira como o currículo afeta a formação do professor em perspectivas diferentes (FERNANDES, 2008; FERNANDES, 2004) ou seja, quão claro e coerente o currículo é para que tais abordagens sejam realmente constitutivas do trabalho desse futuro professor; demonstrando a força do currículo perante a formação de professores, e 1 pesquisa (EMÍLIO, 2008) que faz uma relação entre representações dos professores e as prescrições curriculares.

Dessa forma, consideramos que os trabalhos em questão são interessantes para a área de formação de professores e para a problematização de temáticas relacionadas a currículo, pois auxiliam na compreensão dos motivos pelos quais esse componente que permeia a profissão precisa estar de acordo com as ações do profissional que pretende auxiliar o que 
demanda a apreensão do conceito de currículo, bem como a compreensão de sua constituição, para que então esse se torne um instrumento para o professor, oportunizando a este a tomada de decisões em relação a sua prática e, portanto, seu empoderamento.

\section{Conclusão}

Defendemos que compreender o currículo significa reconhecer explicitamente que as escolhas que fazemos são marcadas por valores, e que temos responsabilidades enquanto professores neste processo essencialmente ideológico que é educar. Neste sentido essa compreensão torna-se indispensável para a formação adequada do profissional docente, o qual a partir deste estudo poderá compreender melhor seus deveres e direitos e se tornar capaz de modificar o contexto no qual está inserido.

De acordo com os estudos relatados aqui, é possível evidenciar potencialidades no desenvolvimento do currículo, a fim de auxiliar na sua (re)estruturação de acordo com a realidade em que será aplicado, evidenciando o empoderamento dos profissionais orientados por estes estudos.

As pesquisas que atentam para o currículo não são novidades para a academia, esse tema tem sido discutido ao longo de muitas décadas, entretanto, devemos destacar que ainda há espaço para muitas pesquisas, uma vez que diversas problemáticas - por exemplo: as relações de poder que permeiam o currículo, as políticas educacionais vigentes constitutivas do currículo, os componentes curriculares, os diversos currículos que regem um determinado sistema de ensino, entre outras - permeiam o tema.

Lidar com tais questões pode possibilitar a compreensão não só das dimensões de um currículo, mas também seu reflexo no contexto ao qual se destina, tanto para as instituições quanto para docentes e alunos. Além disso, ainda há a necessidade de que esses estudos causem maior impacto no contexto de formação inicial, pois na maioria das vezes, os estudantes se graduam e atuam no ambiente escolar sem conhecer a fundo tal ferramenta de trabalho.

Para gerar discussões relevantes em relação a esse tema, alguns questionamentos são sugeridos: Como se caracteriza o currículo e seus reflexos nas ações docentes? Como se dá o processo de construção do currículo em determinada instituição formadora? O que subjaz a construção de um currículo? Qual é o papel do currículo no processo de construção identitária dos envolvidos no contexto em que ele está instituído? 
Estudos que possam revelar-se como referências em relação à importância deste instrumento, como já discutido neste trabalho, considerando que os currículos são permeados pelos contextos sociohistórico micro (local) e macro (político, econômico, nacional, e/ou internacional), os quais são determinantes nas ações do professor, da mesma maneira que são constituídos por este profissional, constituem a sua identidade.

Entretanto, é necessário que se considere a natureza "vaga" do currículo compreendido apenas como um texto prescritivo para a docência, levando em consideração o fato de tal formato possibilitar que o docente tenha certa liberdade para definir suas ações, o que pode ser considerado um ponto favorável ao trabalho a ser desenvolvido, o que não finda tal questão, já que por outro lado, essa vaguidão pode vir a desestruturar o docente que não se sentir capacitado para exercer tal autonomia, desencadeando um processo de representações pessoais negativas por parte destes professores. Portanto, mais uma vez, ressaltamos a necessidade de formar professores hábeis a lidarem com o currículo, problematizando o currículo logo na formação inicial.

\section{Referências}

COOPER, K., \& OLSON, M. R. The multiple "I's" of teacher identitity. In: Kompf, et al (eds) Changing research and practice: Teachers' professionalism, identities and knowledge. (p.78-89). London/Washington, DC: The palmer press, 1996.

COSTA, A. J. H. A formação de professores de inglês: um estudo comparativo de currículos universitários. 01/12/2004. 1v. 213p. Dissertação (Mestrado em Educação) - Universidade Luterana do Brasil, Canoas.

DEWEY. J. Como Pensamos. São Paulo: Nacional, 1959.

EMILIO, R.M. Ensino de língua inglesa no ensino fundamental: aproximação às representações sociais de professores sobre o componente curricular. 01/08/2008. 1v. 173p. Dissertação (Mestrado em Educação) - Universidade Católica de Santos, Santos.

ENGESTRÖM, Y. Learning by expanding: an activity-theoretical approach to developmental research. Helsisnki: Orienta-Konsultit, 1987. Disponível em http://lchc.ucsd.edu/MCA/Paper/Engestrom/expanding/toc.htm Acessado em 05 de abril de 2010 .

FERNANDES, F.P.F. Formas de Organização de Estágios Curriculares em Cursos de Licenciatura em Letras. 01/06/2008. 1v. 242p. Dissertação (Mestrado em Educação) Universidade Federal de Santa Maria, Santa Maria.

FERNANDES, J.S. Currículo de Língua Inglesa na Licenciatura: A Construção do Professor Cidadão. 01/02/2004. 1v. 232p. Dissertação (Mestrado em Lingüística Aplicada e Estudos da Linguagem) - Pontifícia Universidade Católica de São Paulo, São Paulo. 
FREIRE, P. Pedagogia do oprimido. Rio de Janeiro: Paz e Terra, 1970.

FREIRE, P. \& SHOR, I. Medo e Ousadia: 2.ed.o cotidiano do professor. Rio de Janeiro: Paz e Terra, 1986.

GIMENEZ, T. \& FURTOSO, V. B. Racionalidade Técnica e A Formação de Professores de Lingua Estrangeira em um Curso de Letras. In: Revista X, V.2, 2008 p. 1-15.

GIROUX, H.A. Os professores como intelectuais: Rumo a uma pedagogia crítica da aprendizagem. Porto Alegre: Artmed, 1997.

GOODLAD, J.I. Curriculum Inquiry. New York: Mc Graw-Hill Book Company, 1979.

HOLANDA, M.L.O. A formação de professores no Brasil e na Inglaterra - uma análise comparativa. 01/07/2001. 1v. 395p. Doutorado. Universidade Federal do Ceará - Educação, Fortaleza.

MOSCOVICI, S. Representações Sociais: investigações em psicologia social. Trad. Por Guareschi, Pedrinho A. Petrópolis, RJ: Vozes, 2003.

NEWMAN, F.; HOLZMAN, L. Lev Vygotsky: cientista revolucionário. Trad. Marcos Bagno. São Paulo: Edições Loyola, 1993/2002.

PICONI, L. B. Formação de Professores de Língua Inglesa numa Abordagem SócioHistórico-Cultural: A Produção do Currículo em Questão. 30/01/2008. 1v. p.158. Mestrado: Universidade Estadual de Londrina, Londrina.

REIS, S. Pesquisa em Letramento Crítico no Brasil: Um levantamento de dissertações e teses de 1987 a 2006. In: Andrade, O.G.; Durão, A.B.A.B.; Reis, S. Reflexões rumo sobre o Ensino das Línguas Estrangeiras. Londrina: Moriá, 2008.

ROGOFF, Barbara. Observing sociocultural activity on three planes: participatory appropriation, guided participation, and apprenticeship. In: J. Wertsch; P. Del Rio e A. Alvarez (eds.). Sociocultural studies of the mind. Cambridge University Press, 1995, p. 139164.

SILVA, Tomaz Tadeu. Documentos de identidade: uma introdução às teorias do currículo. Belo Horizonte: Autêntica, 2004.

VYGOTSKY, L. S. A Formação Social da Mente: o desenvolvimento dos processos psicológicos superiores. Orgs. Michael Cole et al., 1978. Trad. José Cipolla Neto et al. 6 . Edição. São Paulo: Martins Fontes, 1998.

WERTSCH, J. Voices of the mind: a sociocultural approach to mediated action. Cambridge University Press, 1991. 